\title{
OPTIMASI PENDISTRIBUSIAN AIR DENGAN MENGGUNAKAN METODE LEAST COST DAN METODE MODIFIED DISTRIBUTION (Studi Kasus: PDAM Kabupaten Minahasa Utara)
}

\author{
Claudia Nelwan $^{1)}$, John S. Kekenusa ${ }^{1)}$, Yohanes Langi ${ }^{1)}$ \\ ${ }^{1)}$ Program Studi Matematika FMIPA Universitas Sam Ratulangi \\ Jl. Kampus Unsrat, Manado 95115 \\ e-mail : claudianelwan@ymail.com ; johnskekenusa@yahoo.com ; yarlangi@yahoo.com
}

\begin{abstract}
ABSTRAK
Model optimasi merupakan salah satu model analisis sistem yang diindentikkan dengan operation research. Model transportasi berkaitan dengan penentuan rencana biaya terendah untuk mengirimkan satu barang dari sejumlah sumber (misalnya, pabrik) ke sejumlah tujuan (misalnya, gudang). Prinsip kerja metode least cost ialah pemberian prioritas pengalokasian yang mempunyai ongkos satuan terkecil (biaya per unit terkecil). Metode MODI (Modified Distribution) merupakan metode penyelesaian kasus transportasi yang di kembangkan dari metode stepping stone. Tujuan penelitian ini, menentukan distribusi air yang optimal dengan biaya distribusi yang minimum. Hasil penelitian menunjukkan bahwa biaya operasional yang dikeluarkan sebelum dilakukan minimalisasi yaitu Rp. 603.364.240 dan biaya operasional yang dikeluarkan setelah diminimalisasi menggunakan metode least cost yaitu Rp. 588.814.656.
\end{abstract}

Kata kunci : Least cost, modified distribution, optimasi, pendistribusian air

\section{OPTIMIZATION OF WATER DISTRIBUTION USING LEAST COST METHOD AND MODIFIED DISTRIBUTION METHOD (Case Study on PDAM North Minahasa District)}

\begin{abstract}
Optimization model is one of model in system analysis model identified with operations research. Transport models related to the determination of the lowest cost plan to send an item from a source to a destination. The procedure of the least cost method is giving priority allocation that has the smallest unit cost (cost per unit of the smallest). MODI method (Modified Distribution) is a method of resolving cases of transport that was developed methods stepping stone. The objective from the reseach is determining optimal water distribution with the cost of minimum. The research that has been gained operating costs incurred prior to the minimization of $\mathrm{Rp}$. 603.364.240 and operating cost incurred after minimized using the least cost method is Rp. 588.814.656.
\end{abstract}

Keywords: Least cost, modified distribution, optimization, water distribution

\section{PENDAHULUAN}

Saat ini, air bersih yang merupakan kebutuhan utama sehari-hari masyarakat semakin sulit didapatkan terutama di kotakota besar karena pencemaran air tanah, pencemaran di aliran sungai karena sampah, pencemaran dari industri, dan lain-lain. Kebutuhan akan air bersih yang terus bertambah, sedangkan air bersih yang tersedia di alam semakin berkurang, maka untuk memenuhi kebutuhan air bersih, dibutuhkan suatu badan usaha atau organisasi yang mengelolanya guna memenuhi kebutuhan masyarakat akan air bersih.

Untuk menjalankan kegiatannya PDAM harus mempertimbangkan prinsip ekonomi, yaitu dengan pengeluaran yang minimal dapat menghasilkan kinerja yang maksimal, dalam hal ini memenuhi kebutuhan konsumen akan air bersih. Tentu saja dalam mencapai tujuan tersebut PDAM menemui beberapa kendala, diantaranya :

1. Keterbatasan alat produksi air bersih 
2. Terbatasnya ketersediaan air bersih yang akan didistribusi ke wilayah - wilayah tujuan.

3. Terbatasnya biaya operasional

4. Kebutuhan masyarakat akan air bersih semakin meningkat sehingga perlu sumber air, pompa dan pipa distribusi yang baru.

Indriyani (2004) berpendapat bahwa pengembangan wilayah merupakan salah satu permasalahan yang sering dihadapi oleh Perusahaan Daerah Air Minumyang diakibatkan pertambahan jumlah penduduk yang sangat pesat di daerah perkotaan, sedangkan jumlah air relatif terbatas untuk dapat melayani kebutuhan akan air bersih.

Model optimasi merupakan salah satu model analisa sistem yang diindentikkan dengan operation research (Qomariyah, 1995).

Berdasarkan uraian di atas, maka tujuan utama dari penelitian ini ialah mengembangkan model optimasi distribusi air minum dengan menggunakan parameter model berupa biaya, nilai permintaan dan pasokan air, di suatu wilayah pengelolaan dari Perusahaan Air, menggunakan metode least cost dan modified distribution untuk mencari solusi agar distribusi air merata di semua wilayah.

\section{TINJAUAN PUSTAKA}

\section{PDAM Minahasa Utara}

Perusahaan Daerah Air Minum (PDAM) Kabupaten Minahasa Utara merupakan salah satu perusahaan milik pemerintah kabupaten Minahasa Utara, yang bertugas menyediakan air bersih bagi masyarakat yang ada di Kabupaten Minahasa Utara. PDAM Kabupaten Minahasa Utara saat ini memiliki jumlah pelanggan sebanyak 8985 pelanggan sambungan rumah.

\section{Air bersih}

Air bersih merupakan air yang dipakai untuk keperluan sehari-hari yang kualitasnya memenuhi syarat kesehatan dan dapat diminum apabila telah dimasak. (Yunus dan Witarso, 1992).

Air minum adalah air jernih, yang tidak berbau, tidak berwarna, tidak berasa, dan rasa segar oleh kandungan oksigen (Izdihar dan Hadi, 1998).

\section{Operasi Riset}

Operasi riset digambarkan sebagai suatu pendekatan ilmiah kepada pengambilan keputusan yang meliputi operasi dari sistem sistem organisasi, dan berusaha menetapkan arah tindakan terbaik (optimum) dari sebuah masalah keputusan di bawah sumber daya yang terbatas ( Ismaniah, 2009 ).

\section{Model Transportasi}

Asumsi dasar model ini adalah biaya transport pada suatu rute tertentu proporsional dengan banyaknya unit yang dikirimkan. ( Subardi, 1992 ).

\section{Metode Least Cost}

Prinsip kerja metode ini ialah pemberian prioritas pengalokasian yang mempunyai ongkos satuan terkecil (biaya per unit terkecil). Pengalokasian awal yaitu pada kotak dalam tabel yang mempunyai biaya terendah.

Langkah - langkah dari metode least cost ialah sebagai berikut :

1. Mengalokasikan sebanyak mungkin ke kotak feasible dengan biaya transportasi yang minimum, kemudian harus disesuaikan dengan kebutuhan yang ada.

2. Langkah tersebut diulangi ke biaya minimum terendah selanjutnya.

\section{Metode MODI ( Modified Distribution )}

Pengoperasian metode MODI dalam menyelesaikan masalah transporatasi, prinsip dasarnya sama dengan metode yang lain.

Untuk mencari nilai sel bukan basis berdasarkan Metode MODI, dilakukan dengan cara menambahkan satu baris katakanlah $\mathrm{Kj}$ yang menyatakan nilai setiap kolom $\mathrm{K}_{1}, \mathrm{~K}_{2}, \mathrm{~K}_{3}, \ldots, \mathrm{Kj}$, dan menambahkan satu kolom katakanlah Ri yang menyatakan nilai setiap baris $R_{1}, R_{2}, R_{3}, \ldots$, Ri. Nilai $K j$ dan Ri yang dicari hanya untuk sel basis (jumlah sel basis sama dengan $m+n-1$ ), dengan menggunakan rumus $\mathrm{Ri}+\mathrm{Kj}=\mathrm{Cij}=$ biaya angkut per satuan dari tempat asal (i) ke tempat tujuan (j). Sedangkan untuk mencari nilai sel bukan basis digunakan rumus $\mathrm{Cij}-$ $\mathrm{Ri}$ - Kj. Langkah awal metode MODI dapat dimulai dari tabel awal metode NW-corner maupun tabel awal metode biaya minimum ( Yamit, 1994 ). 


\section{METODOLOGI PENELITIAN}

\section{Objek Penelitian}

Penelitian dilakukan di Perusahaan daerah air minum kabupaten Minahasa Utara. Dimana difokuskan pada masalah ketersediaan dan pendistribusian ke rumah pelanggan. Biaya pendistribusiannya merupakan biaya operasional termasuk dengan biaya pipa, listrik dan biaya untuk pekerja

\section{Data yang digunakan}

PDAM kabupaten Minahasa Utara memiliki 7 wilayah distribusi air dengan masing -masing wilayah memiliki sumber air yang diproduksi dan langsung dialirkan ke wilayah tersebut. Untuk total penawaran air yang didistribusikan yaitu data per hari di tahun 2011, begitu juga dengan data permintaan pelanggan. Diagram sumber ke daerah tujuan yaitu :

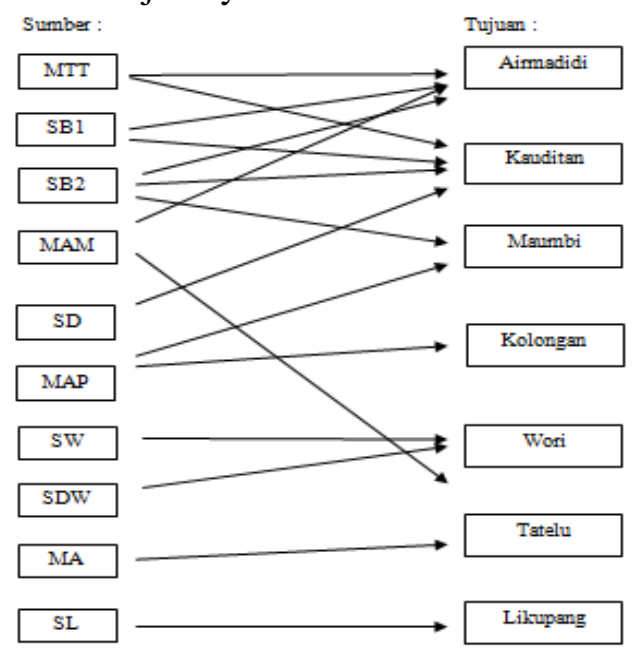

Gambar 1 Sumber dan tujuan pada model transportasi distribusi air

\section{Tahap Penelitian} antara lain :

Langkah - langkah dalam penelitian

Langkah-langkah metode least cost adalah sebagai berikut:

1. Pilih variable Xij (kotak) dengan biaya transport $\left(\mathrm{c}_{\mathrm{ij}}\right)$ terkecil dan alokasikan sebanyak mungkin.

2. Dari kotak-kotak sisanya yang layak (yaitu yang tidak terisi atau dihilangkan) pilih cij terkecil dan alokasikan sebanyak mungkin.

3. Lanjutkan proses ini sampai semua penawaran dan permintaan terpenuhi (Mulyono, 2002).
Setelah menyelesaikan solusi awal dengan metode biaya terkecil dilanjutkan dengan uji optimalisasi dengan metode Modified Distribution.

1. Menguji apakah $(m+n-1)$ jumlah sel yang terisi.

2. Menghitung harga indeks $\mathrm{R}$ dan $\mathrm{K}$.

3. Menghitung indeks yang ditingkatkan atau sel yang tidak terisi.

4. Jawab optimal dengan jika tidak ada yang bernilai negatif $(\geq 0)$ untuk maksimasi dan tidak ada yang bernilai positif $(\leq 0)$ untuk minimasi ( Siagian, 1987 ).

\section{HASIL DAN PEMBAHASAN}

PDAM bertujuan untuk mengoptimalkan kebutuhan air yaitu dengan mengoptimalkan 10 sumber yaitu : mata air Tambuk Terang, Sumur Bor 1, Sumur Bor 2, mata air Matungkas, Sumur Dalam, mata air Padang, Sungai Wori, Sumur dalam wori, mata air Tatelu, Sungai Likupang.

Biaya operasional rata - rata PDAM per $\mathrm{m}^{3}$ adalah Rp.3400. Biaya operasional tersebut meliputi biaya operasional semua sumber ketujuan dan biaya distribusi ke daerah - daerah.

Tabel 1 Penawaran, Permintaan dan biaya rata - rata

\begin{tabular}{|c|c|c|c|c|}
\hline Datrax $=8$ & & Tempmats & 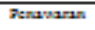 & $=1 y^{2}$ \\
\hline \multirow{4}{*}{ Amieses } & Mart & atoso & 210000 & 2071 \\
\hline & $\operatorname{sen}$ & 5000 & 60200 & 2001 \\
\hline & $m=$ & 105000 & 105000 & reas \\
\hline & $\cos 2$ & 7770 & 2500 & זע \\
\hline \multirow{4}{*}{ xusers } & Mart & 25650 & 23000 & 7005 \\
\hline & $=1$ & 5000 & 5050 & $2 m 1$ \\
\hline & szi: & 10200 & 12100 & $2 \mathrm{ma}$ \\
\hline & 50 & 1980 & 1950 & 2000 \\
\hline Mux=1 & $\operatorname{lng}$ & 20100 & 220000 & 700 \\
\hline \multirow{2}{*}{ rootongas } & $m o$ & 70600 & 760530 & กา \\
\hline & sez: & 10200 & Deto & s11 \\
\hline \multirow{2}{*}{ Wors } & 50 & 7800 & 7800 & 2000 \\
\hline & 5000 & 1700 & 1700 & 2000 \\
\hline \multirow{2}{*}{ Teselu } & $\sin \pi$ & 12800 & 17800 & 2000 \\
\hline & acs & $7 m 0$ & 7200 & 7060 \\
\hline 2ilogesenz & $\mathrm{nz}$ & $m s$ & $7 m s$ & 7000 \\
\hline
\end{tabular}

Untuk sumber - sumber yang tidak dapat mengalirkan air ke daerah tujuan tertentu, maka untuk biaya operasional diisi 
dengan $B$ yaitu dengan menganggap jika mengalirkan air, maka biayanya akan sangat besar. Dari permasalahan ini maka formulasinya yaitu :

Variabel keputusan :

$\mathrm{Xij}=$ Volume air dari sumber $\mathrm{i}$ ke daerah tujuan $\mathrm{j}$

$\mathrm{Cij}=$ Biaya operasional distribusi air dari sumber $\mathrm{i}$ ke daerah tujuan $\mathrm{j}$ dimana $\mathrm{i}=1 \ldots . .10$, $\mathrm{j}=1 \ldots . .7$

Fungsi Tujuan :

Meminimumkan :

$Z=C_{1,1} X_{1,1}+C_{1,2} X_{1,2}+C_{1,3} X_{1,3}+\ldots .+C_{10,7} X_{10,7}$

Kendala :

$\mathrm{X}_{1,1}+\mathrm{X}_{1,2}+\mathrm{X}_{1,3}+\ldots .+\mathrm{X}_{1,7}=\mathrm{a}_{1}$

$X_{2,1}+X_{2,2}+X_{2,3}+\ldots .+X_{2,7}=a_{2}$

$X_{10,1}+X_{10,2}+X_{10,3}+\ldots .+X_{10,7}=a_{10}$

$X_{1,1}+X_{2,1}+X_{3,1}+\ldots .+X_{7,1}=b_{1}$

$X_{1,2}+X_{2,2}+X_{3,2}+\ldots .+X_{7,2}=b_{2}$

$\mathrm{X}_{1,10}+\mathrm{X}_{2,10}+\mathrm{X}_{3,10}+\ldots .+\mathrm{X}_{7,10}=\mathrm{b}_{7}$

Untuk sumber yang tidak mengalirkan air ke daerah tujuan tertentu dialokasikan sebanyak 0 sehingga Formulasi dari permasalahan ini adalah :

Meminimumkan :

$\mathrm{Z}=3071 \mathrm{X}_{1,1}+3808 \mathrm{X}_{1,2}+2961 \mathrm{X}_{2,1}+3991 \mathrm{X}_{2,2}+$ $3420 X_{3,1}+2883 X_{3,2}+4114 X_{3,4}+3183 X_{4,1}+$ $3649 X_{4,6}+3400 X_{5,2}+3649 X_{6,3}+3183 X_{6,4}+$ $3400 X_{7,5}+3400 X_{8,5}+3400 X_{9,6}+3400 X_{10,7}$

Kendala :

$\mathrm{X}_{1,1}+\mathrm{X}_{1,2}=51300$

$X_{2,1}+X_{2,2}=10800$

$X_{3,1}+X_{3,2}+X_{3,4}=30780$

$\mathrm{X}_{4,1}+\mathrm{X}_{4,6}=15540$

$X_{5,2}=1950$

$X_{6,3} X_{6,4}=69120$

$\mathrm{X}_{7,5}=7560$

$\mathrm{X}_{8,5}=1740$

$X_{9,6}=13560$

$X_{10,7}=7776$

$\mathrm{X}_{1,1}+\mathrm{X}_{2,1}+\mathrm{X}_{3,1}+\mathrm{X}_{4,1}=53100$

$\mathrm{X}_{1,2}+\mathrm{X}_{2,2}+\mathrm{X}_{3,2}+\mathrm{X}_{5,2}=41550$

$\mathrm{X}_{6,3}=32200$

$\mathrm{X}_{3,4}+\mathrm{X}_{6,4}=45400$

$X_{7,5}+X_{8,5}=9300$

$\mathrm{X}_{9,6}+\mathrm{X}_{4,6}=20800$

$X_{10,7}=7776$

Dari formulasi tersebut dapat dibentuk ke tabel transportasi yang dapat dilihat pada tabel dibawah ini :
Tabel 2 Transportasi sebelum diminimalisasi



Dari tabel 2 kemudian di modelkan dengan menggunakan diagram transportasi.

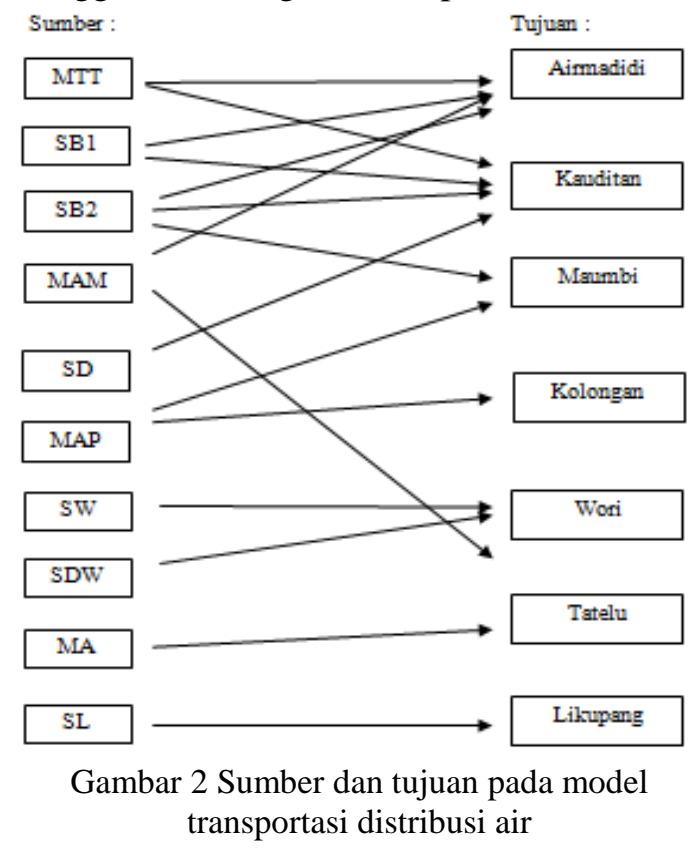

Tabel pendistribusian air diatas tidak bisa dilanjutkan dengan menggunakan metode transportasi karena tidak memenuhi syarat model transportasi. 


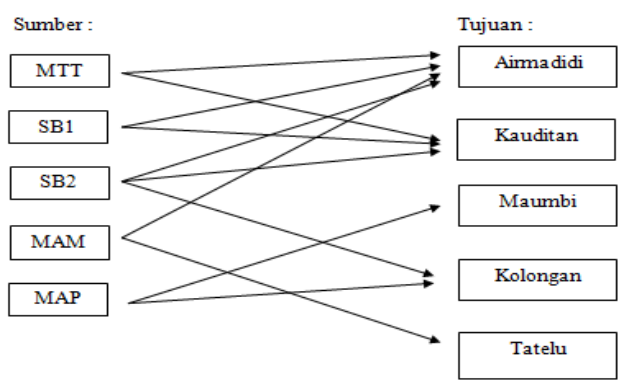

Gambar 3 Sumber dan tujuan pada model transportasi distribusi air

Tabel 3 Transportasi pendistribusian air sebelum diminimalisasi

\begin{tabular}{|c|c|c|c|c|c|c|}
\hline $\mathrm{Ke}^{\mathrm{Dan}}$ & Aimadidi & Kauditan & Maumbi & Kolongan & Tatelu & Supply \\
\hline \multirow{2}{*}{ MTT } & 3071 & 3808 & & & & 51300 \\
\hline & 28400 & 22900 & & & & 31500 \\
\hline \multirow{2}{*}{ SB1 } & 2916 & 3991 & & & & \\
\hline & 6200 & 4600 & & & & 10800 \\
\hline \multirow{2}{*}{ SB2 } & 3420 & 2883 & L & 4114 & 1 & \\
\hline & 10200 & 12100 & & 8480 & & 30780 \\
\hline \multirow[b]{2}{*}{ MAM } & 3183 & & & & 3649 & \\
\hline & 8300 & & & & 7240 & 15540 \\
\hline \multirow[b]{2}{*}{ MAP } & & & 3649 & 3183 & & \\
\hline & & & 32200 & 36920 & & 69120 \\
\hline Demand & 53100 & 39600 & 32200 & 45400 & 7240 & 177540 \\
\hline
\end{tabular}

Biaya operasional pendistribusian air sebelum diminimalisasi

Dari tabel 3 dapat dihitung total biaya transportasi yang dikeluarkan Perusahaan Daerah Air Minum (PDAM) kabupaten Minahasa Utara sebelum dilakukan minimalisasi menggunakan rumus: $\mathrm{Z}=\sum$ ( Biaya operasional pendistribusian air per $\mathrm{m}^{3}$ per daerah pasokan $\mathrm{x}$ jumlah suplai )

$\mathrm{Z}=\sum\left(\mathrm{C}_{1,1} \mathrm{X}_{1,1}+\mathrm{C}_{1,2} \mathrm{X}_{1,2}+\mathrm{C}_{1,3} \mathrm{X}_{1,3}+\ldots .+\mathrm{C}_{5,5} \mathrm{X}_{5,5}\right)$

$=\sum\left(3071 \mathrm{X}_{1,1}+3808 \mathrm{X}_{1,2}+2961 \mathrm{X}_{2,1}+\right.$ $3991 X_{2,2}+3420 X_{3,1}+2883 X_{3,2}+4114 X_{3,4}+$ $\left.3183 \mathrm{X}_{4,1}+3649 \mathrm{X}_{4,5}+3649 \mathrm{X}_{5,3}++3183 \mathrm{X}_{5,4}\right)$

$=\sum((3071 \times 28400)+(3808 \times 22900)+(2961$ $\mathrm{x} 6200)+(3991 \times 4600)+(3420 \times 10200)+$ $(2883 \times 12100)+(4114 \times 8480)+(3183 \times 8300)$ $+(3649 \times 7240)++(3649 \times 32200)+(3183 \times$ 36920))

$$
\text { = Rp. 603.364.240 }
$$

Diperoleh total biaya operasional pendistribusian air Perusahan Daerah Air Minum (PDAM) kabupaten Minahasa Utara sebelum dilakukan minimalisasi yaitu sebesar Rp. 603.364.240 -.

\section{Biaya operasional pendistribusian air dengan menggunakan metode Least Cost}

Prinsip kerja metode ini adalah pemberian prioritas pengalokasian yang mempunyai ongkos satuan terkecil (biaya per unit terkecil). Pengalokasian awal yaitu pada kotak dalam tabel yang mempunyai biaya terendah.

Langkah - langkah dari metode ini adalah

1. Mengalokasikan sebanyak mungkin ke kotak feasible dengan biaya transportasi yang minimum kemudian harus disesuaikan dengan kebutuhan yang ada.

2. Langkah tersebut diulangi ke biaya minimum terendah selanjutnya sampai semua kebutuhan dapat terpenuhi.

Untuk perhitungan iterasi yang dikenakan pada tabel transportasi dengan menggunakan metode least cost dapat dilihat pada tabel 4 .

Tabel 4 Transportasi pendistribusian air setelah diminimalisasi dengan metode least cost

\begin{tabular}{|c|c|c|c|c|c|c|}
\hline $\mathrm{Ke}$ & Airmadidi & Kauditan & Maumbi & Kolongan & Tatelu & Supply \\
\hline \multirow{2}{*}{ MTT } & \begin{tabular}{|l|l|}
3071 \\
\end{tabular} & 3808 & & & & \multirow{2}{*}{51300} \\
\hline & 34000 & 17300 & & & & \\
\hline \multirow{2}{*}{ SB1 } & 2916 & \begin{tabular}{|l|l|}
39911 \\
\end{tabular} & & & L & \multirow{2}{*}{10800} \\
\hline & 10800 & 0 & & & & \\
\hline \multirow{2}{*}{ SB2 } & 3420 & 2883 & L & \begin{tabular}{|l|l|} 
& \\
\end{tabular} & L & \multirow{2}{*}{30780} \\
\hline & 0 & 22300 & & 8480 & & \\
\hline \multirow{2}{*}{ MAM } & 3183 & & & & 3649 & \multirow{2}{*}{15540} \\
\hline & 8300 & & & & 7240 & \\
\hline \multirow{2}{*}{ MAP } & & & 3649 & \begin{tabular}{|l|}
3183 \\
\end{tabular} & & \multirow{2}{*}{69120} \\
\hline & & & 32200 & 36920 & & \\
\hline Demand & 53100 & 39600 & 32200 & 45400 & 7240 & 177540 \\
\hline
\end{tabular}

Dari tabel diatas diperoleh :

$\begin{array}{ll}X_{1,1}=34000 & X_{1,2}=17300 \\ X_{2,1}=10800 & X_{2,2}=0 \\ X_{3,1}=0 & X_{3,2}=22300 \\ X_{3,4}=8480 & X_{4,1}=8300 \\ X_{4,5}=7240 & X_{5,3}=32200 \\ X_{5,4}=36920 & \end{array}$

Dari tabel transportasi yang diperoleh pada tabel diatas maka dapat dihitung total biaya transportasi yang dikeluarkan Perusahaan Daerah Air Minum (PDAM) kabupaten Minahasa Utara setelah dilakukan minimalisasi dengan menggunakan metode least cost menggunakn rumus fungsi tujuan : $\mathrm{Z}=\sum$ ( Biaya operasional pendistribusian air per $\mathrm{m}^{3}$ per daerah pasokan $\mathrm{x}$ jumlah suplai )

$\mathrm{Z}=\sum\left(\mathrm{C}_{1,1} \mathrm{X}_{1,1}+\mathrm{C}_{1,2} \mathrm{X}_{1,2}+\mathrm{C}_{1,3} \mathrm{X}_{1,3}+\ldots .+\mathrm{C}_{5,5} \mathrm{X}_{5,5}\right)$ $=\sum\left(3071 \mathrm{X}_{1,1}+3808 \mathrm{X}_{1,2}+2961 \mathrm{X}_{2,1}+\right.$ $3991 X_{2,2}+3420 X_{3,1}+2883 X_{3,2}+4114 X_{3,4}+$ $\left.3183 \mathrm{X}_{4,1}+3649 \mathrm{X}_{4,5}+3649 \mathrm{X}_{5,3}++3183 \mathrm{X}_{5,4}\right)$

$=\sum((3071 \times 28400)+(3808 \times 22900)+(2961$ x 6200) + (3991 x 4600) + (3420 x 10200) + $(2883 \times 12100)+(4114 \times 8480)+(3183 \times 8300)$ $+(3649 \times 7240)++(3649 \times 32200)+(3183 \times$ 36920))

$=$ Rp. 588.814 .656

\section{Uji optimalisasi}

Setelah dilakukan penyelesaian awal dengan menggunakan metode least cost maka 
dilanjutkan dengan uji optimalisasi dengan menggunakan metode MODI untuk mendapatkan hasil yang optimal. Langkah langkah metode MODI :

1. Menentukan apakah $(m+-1)=$ jumlah sel yang terisi.

Tabel awal metode least cost dapat dilihat pada tabel 6. Jumlah sel yang terisi pada tabel diatas $(m+n-1)$ dimana $m$ adalah baris dan $n$ adalah kolom. Maka hasilnya $(5+5-1)=9$. Karena jumah sel yang terisi 9 maka dilanjutkan dengan langkah berikutnya.

2. Evaluasi dari variabel non basis dengan memisalkan salah satu nilai dari $u_{i}$ atau $v_{j}$ dengan sebarang bilangan bulat tertentu, misalkan : $\mathrm{u}_{1}=0$ sehingga dapat dihitung :

$\mathrm{C}_{11}=\mathrm{u}_{1}+\mathrm{v}_{1} \rightarrow 3071=0+\mathrm{v}_{1} \rightarrow \mathrm{v}_{1}=3071$

$\mathrm{C}_{12}=\mathrm{u}_{1}+\mathrm{v}_{2} \rightarrow 3808=0+\mathrm{v}_{2} \rightarrow \mathrm{v}_{2}=3808$

$\mathrm{C}_{21}=\mathrm{u}_{2}+\mathrm{v}_{1} \rightarrow 2916=\mathrm{u}_{2}+3071 \rightarrow \mathrm{u}_{2}=-155$

$\mathrm{C}_{32}=\mathrm{u}_{3}+\mathrm{v}_{2} \rightarrow 2883=\mathrm{u}_{3}+3808 \rightarrow \mathrm{u}_{3}=-925$

$\mathrm{C}_{34}=\mathrm{u}_{3}+\mathrm{v}_{4} \rightarrow 4114=-925+\mathrm{v}_{4} \rightarrow \mathrm{v}_{4}=5039$

$\mathrm{C}_{41}=\mathrm{u}_{4}+\mathrm{v}_{1} \rightarrow 2883=\mathrm{u}_{4}+3071 \rightarrow \mathrm{u}_{4}=112$

$\mathrm{C}_{45}=\mathrm{u}_{4}+\mathrm{v}_{5} \rightarrow 3649=112+\mathrm{v}_{5} \rightarrow \mathrm{v}_{5}=3537$

$\mathrm{C}_{53}=\mathrm{u}_{5}+\mathrm{v}_{3} \rightarrow 3649=-1856+\mathrm{v}_{3} \rightarrow \mathrm{v}_{3}=-925$

$\mathrm{C}_{54}=\mathrm{u}_{5}+\mathrm{v}_{4} \rightarrow 3183=\mathrm{u}_{5}+5039 \rightarrow \mathrm{u}_{3}=-1856$

3. Evaluasi dari variabel non basis dengan menghitung nilai dari $Z_{i j}-C_{i j}=u_{i}+v_{j}-c_{i j}$ sehingga diperoleh :

$\mathrm{Z}_{13}-\mathrm{C}_{13}=\mathrm{u}_{1}+\mathrm{v}_{3}-\mathrm{C}_{13}=0+5505-20000=-$ 338

$\mathrm{Z}_{14}-\mathrm{C}_{14}=\mathrm{u}_{1}+\mathrm{v}_{4}-\mathrm{C}_{14}=0+5039-20000=-$ 14961

$\mathrm{Z}_{15}-\mathrm{C}_{15}=\mathrm{u}_{1}+\mathrm{v}_{5}-\mathrm{C}_{15}=0+3537-20000=-$ 16463

$\mathrm{Z}_{22}-\mathrm{C}_{22}=\mathrm{u}_{2}+\mathrm{v}_{2}-\mathrm{C}_{22}=-155+3808-3991=$ $-338$

$\mathrm{Z}_{23}-\mathrm{C}_{23}=\mathrm{u}_{2}+\mathrm{v}_{3}-\mathrm{C}_{23}=-155+5505-20000=$ $-14650$

$\mathrm{Z}_{24}-\mathrm{C}_{24}=\mathrm{u}_{2}+\mathrm{v}_{4}-\mathrm{C}_{24}=-155+112-20000=$ $-15116$

$\mathrm{Z}_{25}-\mathrm{C}_{25}=\mathrm{u}_{2}+\mathrm{v}_{5}-\mathrm{C}_{26}=-155+3537-20000=$ $-16618$

$\mathrm{Z}_{31}-\mathrm{C}_{31}=\mathrm{u}_{3}+\mathrm{v}_{1}-\mathrm{C}_{31}=-925+3071-3420=$ $-1247$

$\mathrm{Z}_{33}-\mathrm{C}_{33}=\mathrm{u}_{3}+\mathrm{v}_{3}-\mathrm{C}_{33}=-925+5505-20000=$ $-15420$

$\mathrm{Z}_{35}-\mathrm{C}_{35}=\mathrm{u}_{3}+\mathrm{v}_{5}-\mathrm{C}_{35}=-925+3537-20000=$ $-17338$

$\mathrm{Z}_{42}-\mathrm{C}_{42}=\mathrm{u}_{4}+\mathrm{v}_{2}-\mathrm{C}_{42}=112+3808-20000=-$ 16080

$\mathrm{Z}_{43}-\mathrm{C}_{43}=\mathrm{u}_{4}+\mathrm{v}_{3}-\mathrm{C}_{43}=112+5505-20000=-$ 14383

$\mathrm{Z}_{44}-\mathrm{C}_{44}=\mathrm{u}_{4}+\mathrm{v}_{4}-\mathrm{C}_{44}=-1856+5039-20000$ $=-14849$

$\mathrm{Z}_{51}-\mathrm{C}_{51}=\mathrm{u}_{5}+\mathrm{v}_{1}-\mathrm{C}_{55}=-1856+3071-$ $20000=-18785$

$\mathrm{Z}_{52}-\mathrm{C}_{52}=\mathrm{u}_{5}+\mathrm{v}_{2}-\mathrm{C}_{52}=-1856+3808-3420=$ $-18048$
$\mathrm{Z}_{55}-\mathrm{C}_{55}=\mathrm{u}_{5}+\mathrm{v}_{5}-\mathrm{C}_{55}=-1856+3537-20000$ $=-18319$

Karena tidak ada nilai dari $\mathrm{Zij}$ - Cij yang positif ( $\mathrm{Zij}-\mathrm{Cij}>0)$ maka tabel sudah optimal. Hasil pengolahan manual ini sama dengan hasil dari pengolahan dengan software QM ( Quantitative Method) for windows 2.0

\section{KESIMPULAN}

Dari hasil dan pembahasan diperoleh solusi optimal yaitu sumber mata air Tambuk Terang ke tujuan Airmadidi, dengan volume air sebelumnya yaitu $28400 \mathrm{~m}^{3} /$ bulan berubah menjadi 34000 , sumber mata air Tambuk Terang ke tujuan Kauditan, volume air sebelumnya yaitu $22900 \mathrm{~m}^{3} /$ bulan berubah menjadi 17300, sumber Sumur Bor 1 ke tujuan Airmadidi, volume air sebelumnya yaitu $6200 \mathrm{~m}^{3} /$ bulan berubah menjadi 10800 , sumber Sumur Bor 1 ke tujuan Kauditan, volume air sebelumnya yaitu $4600 \mathrm{~m}^{3} /$ bulan berubah menjadi 0, sumber Sumur bor 2 ke tujuan Airmadidi, volume air sebelumnya yaitu $10200 \mathrm{~m}^{3} /$ bulan berubah menjadi 0 , sumber Sumur Bor 2 Kauditan, volume sebelumnya yaitu $12100 \mathrm{~m}^{3} /$ bulan berubah menjadi 22300 dengan biaya operasional yang dikeluarkan sebelum diminimalisasi yaitu Rp. 603.364.240 dan setelah diminimalisasi menggunakan metode least cost yaitu Rp. 588.814.656.

\section{DAFTAR PUSTAKA}

Anonim, 2012. Profil PDAM Minahasa Utara. PDAM Minahasa Utara. Minahasa Utara.

Indryani, R. Suprayitno, H. Dan Astana, I. N. Y. 2004. Model Transportasi Untuk Pengembangan Air Bersih di Kabupaten Badung, Provinsi Bali. Jurnal Teknologi dan Rekayasa Sipil Jurusan Teknik Sipil Institut Teknologi Sepuluh November. Surabaya Edisi Maret Hal. 19-28

Ismaniah. 2009. Penyelesaian Masalah Riset Operasi dengan Menggunakan Program Solver. Jurnal Kajian Ilmiah Lembaga Penelitian Ubhara Jaya Vol.10 No.1, P: 973-988

Izdihar dan Hadi, F. 1998. Air Minum. Yayasan Lembaga Pendidikan Masalah Bangunan. Bandung. 
Mulyono, S. 2002. Riset Operasi. Fakultas Ekonomi Universitas Indonesia. Jakarta.

Qomariyah, S. 1995. Analisis Sistem dalam Perencanaan dan Pengembangan Sumber Daya Air. Prosiding Pertemuan Ilmiah Tahunan (PIT) XII Himpunan Ahli Teknik Hidraulik Indonesia (HATHI) Surabaya. 21 - 23 November. Vol.1 Hal $9-16$.

Siagian, P. 1987. Penelitian Operasional Teori dan Praktikum. Universitas Indonesia. Jakarta.

Subardi, A. 1992. Metode Modified Distribution Dalam Operations Research. Jurnal dan Prosiding Manajemen dan Usahawan Vol.21 No.05, P: 2-7

Yamit, J. 1994. Manajemen Kuantitatif Untuk Bisnis. BPFE. Yogyakarta.

Yunus, I Y., dan WS. Witarso. 1992. Spesifikasi Sumur Gali Untuk Sumber Air Bersih. Badan Standarisasi Nasional. 